\title{
A IMPORTÂNCIA DO TRABALHO DAS OUVIDORIAS NAS ENTIDADES FECHADAS DE PREVIDÊNCIA COMPLEMENTAR - EFPC - FUNDOS DE PENSÃO
}

\author{
Maria Isabel da Silva Tavares ${ }^{1}$
}

\begin{abstract}
Resumo
A proposta deste trabalho é incentivar a criação da Ouvidoria na estrutura organizacional das Entidades Fechadas de Previdência Complementar - EFPC, com a sua devida normatização através do órgão regulador Previc - Superintendência Nacional de Previdência Complementar, apresentando a importância do serviço como um canal ativo da geração 4.0, que significa ouvir, resolver, melhorar e participar. Buscando a redução dos processos judiciais que crescem nesse segmento a cada dia, através da mediação de conflitos e um relacionamento confiável entre a instituição e o seu público-alvo, os participantes ativos e assistidos.
\end{abstract}

Palavras-chave: Ouvidoria. Entidades Fechadas de Previdência Complementar.

\begin{abstract}
The purpose of this work is to encourage the creation of the Ombudsman's Office in the organizational structure of the Closed Complementary Pension Funds (EFPC), with its proper regulation through the regulatory agency Previc - National Superintendence of Supplementary Pension, presenting the importance of the service as an active channel 4.0, which means listening, resolving, improving, and participating. Seeking to reduce the lawsuits that grow in this segment every day, through the mediation of conflicts and a reliable relationship between the institution and its target audience, active and assisted participants.
\end{abstract}

Keywords: Ombudsman. Closed Supplementary Pension Entities.

DOI:10.37814/2594-5068.2020v3.p173-181

1 Bacharel em Relações Públicas pela Escola Superior de Relações Púbicas - ESURP. Pós-graduada em Gestão de Ouvidoria pela Escola Superior de Relações Públicas - Esurp; Recursos Humanos - Potencial Humano nas Organizações pela Faculdade de Ciências e Administração de Pernambuco - FCAP. Ouvidora há 11 anos, atualmente é Ouvidora da Fundação Chesf de Assistência e Seguridade Social - Fachesf. (Isa-bellt1517@gmail.com.) 


\section{INTRODUÇÃO}

Vivemos em um mundo que está em constante evolução e a era da informação veio para quebrar antigas crenças e estabelecer novas conexões entre indivíduos e corporações, e nesse sentido enfatizamos a Ouvidoria como um importante canal de diálogo e escuta, que desenvolve competências para dar voz àqueles que procuram o serviço. Neste artigo buscamos apresentar a importância da implantação da Ouvidoria nas Entidades Fechadas de Previdência Complementar - EFPC, diminuindo ações judiciais através da mediação e diálogo permanente, buscando a redução de conflitos nas entidades com seu público-alvo.

A previdência complementar fechada integra o sistema de previdência social brasileiro e constitui importante instrumento de proteção adicional ao trabalhador e mecanismo de formação de poupança interna de longo prazo, necessário para ampliar a capacidade de investimento do País e diversificar as fontes de financiamento do crescimento econômico.

As entidades fechadas de previdência complementar (EFPC), conhecidas popularmente como fundos de pensão, são organizadas por empresas e associações com o objetivo de garantir a seus empregados ou associados uma complementação à aposentadoria oferecida pelo Regime Geral de Previdência Social (operacionalizado pelo Instituto Nacional de Seguridade Social - INSS), por meio da administração de planos de benefícios. Os planos de benefícios administrados por essas entidades podem garantir, além da complementação à aposentadoria, proteção contra eventos não programados, como morte, doença, invalidez, entre outros, a depender do regulamento do plano.

As EFPC são mantidas pelas contribuições do empregador e do empregado, que são vertidas aos respectivos planos de benefícios, para serem investidas e retornarem, na forma de renda, ao empregado no momento da aposentadoria. Quando os fundos são oferecidos por associações ou entidades de classe, o processo ocorre da mesma maneira, mas as contribuições serão feitas apenas pelos associados.

De acordo com MARTINEZ (1996), o primeiro fundo de pensão surgido no Brasil, em abril de 1904, com as características de fundo fechado, foi a Caixa de Previdência dos Funcionários do Banco do Brasil S.A. - Previ, com patrimônio equivalente a $27 \%$ do volume total de fundos de pensão. Alguns anos depois, em 1967, surge o Fundo de Beneficência aos Funcionários do Banco do Estado do Paraná S.A. - Funbep, e em seguida, no ano de 1970, surge a Petros - Fundação Petrobrás de Seguridade Social.

O ambiente institucional da previdência fechada evoluiu bastante nas últimas três décadas. $\mathrm{O}$ acesso que antes praticamente se restringia a trabalhadores de grandes empresas (estatais e multinacionais) tem se diversificado de forma significativa, inclusive através da criação de planos instituídos por associações e entidades classistas e da aprovação da previdência fechada dos servidores públicos.

Atualmente, o sistema de previdência complementar fechado conta com mais de 300 EFPC que administram, aproximadamente, 1.100 planos, oferecendo proteção previdenciária a cerca de 6 milhões de brasileiros, entre participantes ativos, inativos e assistidos. Tais números colocam o Brasil como o oitavo maior sistema de previdência complementar do mundo em termos absolutos 
(ativo total). A supervisão e a fiscalização do sistema de previdência complementar fechado são realizadas pela Superintendência Nacional de Previdência Complementar - Previc (PREVIC, 2012).

\section{DESENVOLVIMENTO}

\subsection{Fundamentação Teórica}

O serviço de Ouvidoria não é normatizado pelo órgão regulador, a Previc, que foi criada em 2010 substituindo a SPC - Secretaria de Previdência Complementar, porém a própria autarquia tem o canal de Ouvidoria através do acesso: http://www.previc.gov.br/acesso-a-informacao/participacao-social/ouvidoria, porém não exige legalmente que as entidades a qual regula tenham o canal, apenas faz uma recomendação através do Guia de Melhores Práticas em Fundos de Pensão, elaborado em agosto de 2010, no qual visa buscar a melhor estrutura organizacional para as fundações.

Recomenda-se que a entidade analise a viabilidade de criação de uma Ouvidoria ou canal de comunicação com empregados, patrocinadores, instituidores, participantes e assistidos, como forma de organizar e acompanhar o recebimento de solicitações, questionamentos, denúncias e representações. (GUIA DE MELHORES PRÁTICAS)

Essa recomendação eleva a importância da Ouvidoria dentro das organizações a fim de caminhar lado a lado Do Gestor/Diretor, fazendo o elo entre os deveres e as obrigações das entidades para com seus usuários. O cenário, porém, propiciou a criação de centrais de relacionamento/SAC e não de Ouvidorias.

Importante esclarecer que existe um diferencial entre a Ouvidoria e as centrais de relacionamento. As Ouvidorias têm como meta a proposição da mudança nos processos internos, devem ser ligadas à alta gestão da entidade e trabalham de forma autônoma, atuando em conformidade com as normas e regras das entidades. A Ouvidoria trabalha não apenas de forma corretiva, mas, e principalmente, de forma preventiva, tendo ação estratégica numa empresa/órgão/instituição, enquanto os serviços de atendimento, centrais de relacionamento, atendem situações rotineiras com atuações operacionais.

MERCER (2015) exemplifica algumas ações de melhorias de uma Ouvidoria no segmento de previdência complementar fechada, como:

1. Pode-se obter queda no número dos processos julgados pela Câmara de Recursos da Previdência Complementar - CRPC, considerando a resolução satisfatória dos casos analisados pelo Ouvidor.

2. Mediar os conflitos de forma mais eficiente, entre um participante ou assistido em relação às ações tomadas pelas áreas da EFPC.

3. Redução do número de ações judiciais dos participantes e assistidos contra a EFPC.

4. Identificar problemas operacionais na EFPC em relação ao plano de benefícios ou serviços e, em casos de julgamento no Conselho Deliberativo, que é a última instância dos processos adminis- 
trativos, oferecer fundamentos técnicos para melhorar a defesa das EFPC, ampliando as chances de êxito.

5. Propor ao Conselho Deliberativo ou à diretoria da EFPC medidas corretivas ou de aprimoramento de procedimentos e rotinas, em decorrência da análise das reclamações recebidas e deficiências identificadas.

6. Maior credibilidade e fortalecimento da imagem da EFPC perante participantes e assistidos.

7. Melhoria na comunicação e entendimentos dos planos de benefícios ofertados pelas EFPC.

Destacamos que alguns Fundos de Pensão, previdência fechada, já implantaram a área de Ouvidoria, mesmo não sendo a implantação obrigatória e normatizada pelo órgão regulador. Fundos de pensão como:

- Economus - Constituído pelo antigo Banco Nossa Caixa S/A e incorporado pelo Banco do Brasil em 2009, que assumiu o patrocínio do Plano, o Economus - Instituto de Seguridade Social é uma Entidade Fechada de Previdência Complementar, constituída exclusivamente para os funcionários do banco e do próprio Economus. A Ouvidoria funciona desde 2014.

- Fachesf - Criada em 10 de abril de 1972 pela Companhia Hidro Elétrica do São Francisco (Chesf). Administra planos de previdência para os empregados e aposentados da Chesf e da Fachesf, além de oferecer diversos outros serviços, tais como plano de saúde, seguro de vida e empréstimos. A Ouvidoria funciona desde 2014.

- Funcesp - Criada em 2 de dezembro de 1968 pela Assembleia Geral Extraordinária da Cesp, delibera a constituição de uma fundação para administrar os recursos destinados à assistência social de seus empregados. A Ouvidoria funciona desde 2011.

Enfatizamos que deve haver uma normatização com regras claras, existindo uma visão diferenciada da alta gestão para com a área de Ouvidoria dentro das EFPC, conforme disposto na Resolução CNSP n 279/2013, Art. $4^{\circ}$, V: "propor ao conselho de administração ou, na sua ausência, à diretoria da entidade, medidas corretivas ou de aprimoramento de procedimentos e rotinas, em decorrência da análise das reclamações recebidas e deficiências identificadas".

Destacamos algumas resoluções normativas que obrigam a implantação da Ouvidoria nas instituições:

- 2007 - Bacen (Banco Central do Brasil) - Resolução n 3.477, torna obrigatória a criação de Ouvidoria pelo mercado regulado pelo órgão.

- 2012 - CVM (Comissão de Valores Mobiliários) - Instrução Normativa n 529, que entrou em vigor em $1^{\circ}$ de julho de 2013 , também torna obrigatória a criação de Ouvidorias por empresas reguladas pelo órgão.

- 2013 - CNSP (Conselho Nacional de Seguros Privados ) - Edita a resolução n 279, tornando obrigatória a criação de Ouvidorias pelas empresas reguladas pela autarquia.

- 2013 - ANS (Agência Nacional de Saúde Suplementar) - Publica a resolução n 323, tornando obrigatória a constituição de Ouvidoria pelo seu mercado supervisionado. 


\subsection{A Gestão da Ouvidoria}

O Ouvidor na sua gestão desenvolve ações alinhadas com o planejamento estratégico da entidade, devendo haver o conhecimento de fatores importantes, tais como a missão e visão da instituição, além de desenvolver habilidades interpessoais para que seja mantido um clima amistoso no seu atendimento na empresa. Para que isso aconteça, são necessárias atitudes voltadas para os desafios da gestão por competência.

O Ouvidor porta-se tendo como diretriz a busca da justiça no dia a dia, não fazendo distinção entre pessoas - todos são iguais perante a Ouvidoria, contrapondo-se a toda forma de manipulação, corporativismo e abuso de poder. Quando o Ouvidor não consegue enfrentar tais questões ou se posicionar de acordo com elas, a Ouvidoria cai no descrédito junto com o Ouvidor, reforçando os vícios detectados na ausculta da comunidade e a supressão da razão de ser do instituto (VILANOVA et al., 2012).

\subsection{Organograma contendo a área de Ouvidoria na estrutura organizacional}

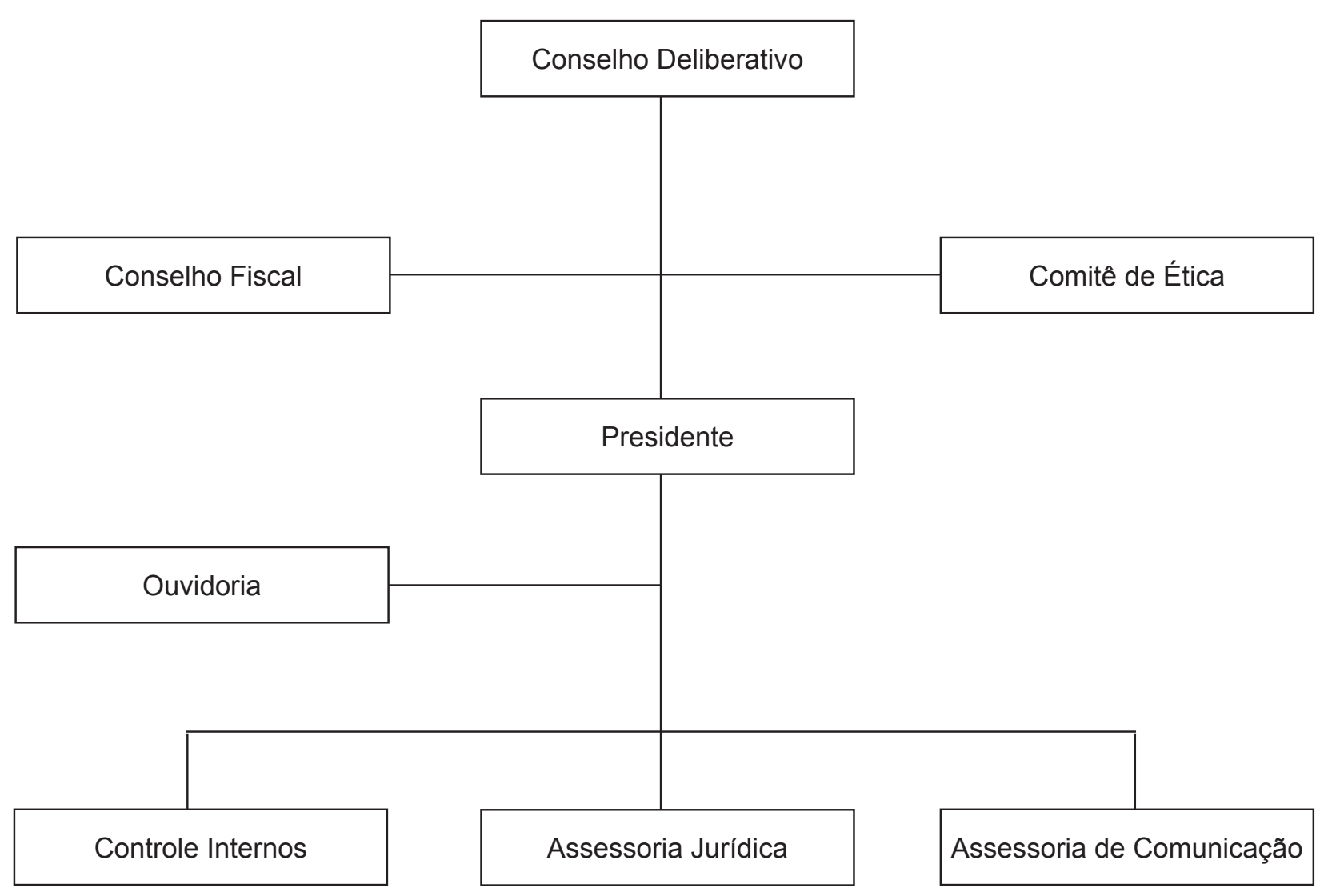

A Ouvidoria é uma unidade autônoma, devendo ser ligada à alta direção da organização (Diretor-Presidente). 


\section{METODOLOGIA}

A Ouvidoria deve buscar alternativas viáveis no sentido de proporcionar condições para cumprir com as suas finalidades primordiais de promover a conciliação e a mediação na resolução de conflitos entre os demandantes e a instituição, evitando assim que aqueles prossigam com as reclamações através de ações judiciais, que podem levar anos para sua solução, envolvendo elevado dispêndio para as partes.

MERCER (2015) afirma que a Ouvidoria, após receber, identificar, verificar e conferir com a área envolvida a reclamação recebida, e sempre que se observar injustiça ou erro, poderá colocar esse direito em prática e exercer o acompanhamento das ações e da atuação da entidade ou instituição, como meio de colaborar para o seu fortalecimento e desenvolvimento.

Além de fortalecer a entidade com ações atuantes, a Ouvidoria, através do serviço da Ouvidoria ativa denominada geração 4.0, que significa ouvir, resolver, melhorar e participar, deve satisfazer o "cliente", permitindo que sua participação no processo seja legítima. Para KOTLER e ARMSTRONG (1999), satisfação dos clientes significa atender às suas expectativas sobre produtos e serviços. Essas expectativas são criadas de acordo com a perspectiva de utilização do serviço anterior, das opiniões de amigos e familiares e de campanhas publicitárias que influenciaram suas decisões de consumo.

A participação dos clientes evita os famosos "ruídos" de comunicação entre a entidade e o seu público de interesse, e eles são denominados, conforme Lei Federal Complementar $n^{\circ} 109$, art. $8^{\circ}$ de 2001, que dispõe sobre o Regime da Previdência Complementar: "participantes ativos", os que contribuem para o plano previdenciário e ainda não recebem seus benefícios, e "participantes assistidos", os que recebem benefícios do plano (aposentadorias e pensão).

Uma das formas de participação é a criação de um Comitê de Assistidos, composto apenas pelos participantes assistidos.

Para as EFPC, esse modelo possibilita que a Ouvidoria possa agregar valor disseminando informações relevantes da entidade para os assistidos, recebendo as críticas e sugestões de meIhorias, dando voz e contribuindo para a melhor gestão da entidade. Nos demais segmentos do mercado, essa metodologia de participação/aproximação é conhecida como conselho de clientes (CLIENTESA, 2013), utilizado em empresas que trabalham com prestação de serviços em diversos segmentos no mercado brasileiro.

\subsection{Formato do Comitê}

O comitê se reúne a cada três meses, trazendo sugestões e informando suas expectativas em relação à entidade, que servem de insumos para uma melhoria contínua, gerando, além da credibilidade, um sentimento de pertencimento, existindo um espaço onde podem conversar e expor suas opiniões.

Os membros do comitê são escolhidos pela Ouvidoria e aprovados pela diretoria da entidade. O número de membros deverá atingir o quantitativo máximo de quinze pessoas e o mandato pode 
ser de até um ano, sem renovação. Dessa forma é possível dar oportunidade a que novos assistidos participem do Comitê.

Outra forma de buscar parceria é através de uma pesquisa de satisfação. Com a pesquisa poderemos mensurar a qualidade do serviço oferecido pela Ouvidoria. Segundo VAVRA (1993, p.164), "se fosse perguntado aos clientes o que mais os satisfazia em relação a um produto ou serviço, uma grande maioria, sem dúvida, responderia: Percepção de Qualidade”. O mesmo autor (1993) afirma ainda que a percepção de qualidade dos clientes é mutável, podendo ser alterada de acordo com o tempo, com as circunstâncias e de cliente para cliente.

\subsection{Formato da Pesquisa de Satisfação}

Para todos os que utilizaram o canal da Ouvidoria, tanto os participantes ativos quanto os participantes assistidos, serão encaminhados formulários eletrônicos por e-mail. A pesquisa deve conter perguntas-chave sobre serviços prestados pela Ouvidoria.

\subsubsection{Perguntas-chave}

1. Qual é o grau de satisfação com a Ouvidoria quanto ao atendimento/tratamento recebido?

2. Qual é o seu grau de satisfação com a Ouvidoria quanto ao tempo de resposta à solicitação?

3. Qual o seu grau de satisfação com a Ouvidoria quanto à resposta/solução apresentada?

4. Qual o seu grau de satisfação com a Ouvidoria quanto ao acompanhamento do seu processo?

5. Você recomendaria a Ouvidoria?

6. Que sugestão você daria para melhorar o serviço?

\subsection{Métrica de Satisfação NPS}

Ao receber as respostas com sugestões e críticas, elas serão analisadas através da métrica de satisfação NPS.

Com a métrica poderemos analisar quem está satisfeito e os insatisfeitos com o serviço, permitindo que a Ouvidoria monitore as recomendações sugeridas e, dessa forma, realize rapidamente intervenções quando forem necessárias.

Agregado à métrica NPS, é necessário definir indicadores de satisfação, para demonstrar índices de melhorias na prestação dos serviços da Ouvidoria.

\subsection{Os Indicadores de Satisfação}

Identificamos 02 indicadores para mensurar a satisfação: 
Quantidade de melhorias recomendadas

Através das recomendações, poderemos analisar a viabilidade da implantação ou melhora do processo proposto.

Quantidade de melhorias implantadas

Poderemos medir a quantidade de melhorias implantadas a partir das propostas recebidas.

\section{CONSIDERAÇÕES FINAIS}

Este artigo pretende analisar como o desenvolvimento de algumas competências do Ouvidor podem contribuir sobremaneira na obtenção de resultados satisfatórios para as EFPC. Segundo ASSUNÇÃO (2012), a Ouvidoria é uma função e, acima de tudo, uma atitude decorrente de um novo pensamento administrativo, que ao nosso ver ainda está, apesar de todos os avanços, em estado embrionário.

Para atender ao sistema previdenciário, a Ouvidoria deverá ser compatível com a natureza e a complexidade dos produtos, planos de benefícios, atividades, processos e sistemas de cada entidade, além de constituída de forma autônoma e independente das demais áreas da EFPC. As EFPC deverão dar ampla divulgação sobre a existência da Ouvidoria, como forma de garantir o pleno acesso do participante e assistido. A Ouvidoria deverá contar com canais ágeis de atendimento, bem como considerar os requisitos de acessibilidades e possuir uma equipe de especialistas multidisciplinares ao seu lado para cumprir as múltiplas missões de sua competência, com expertise nos aspectos técnicos e legais que revestem a matéria (MERCER, 2015).

As sugestões recebidas através do Comitê servem de termômetro para uma análise crítica dos serviços, objetivando viabilizar melhorias contínuas através do diálogo, promovendo a adequada apuração e o tratamento às sugestões propostas, assim como a pesquisa irá medir se houve bom atendimento e o que deve ser melhorado. Com isso se busca também:

- Olhar para fora - Ouvidoria como fonte de análise de sistemas organizacionais e mercados.

- Olhar para dentro - Ouvidoria sugerindo adaptações rápidas da Organização para atendimento aos desafios do ambiente.

- Inovação-Ouvidoria como fonte de estudos para novos produtos e serviços personalizados.

Dessa forma, teremos os benefícios de redução de conflitos e da judicialização nas EFPC em face da necessidade de aperfeiçoar seu atendimento aos participantes e assistidos, porque a repercussão de ações judiciais e dos erros tende a ser mais onerosa a partir da complexidade do negócio dos planos de benefícios. 


\section{REFERÊNCIAS}

ASSUNÇÃO, José Marcelo. Uma falta que faz...Fala e Ouve: O papel pedagógico da Ouvidoria, em IASBECK, Luiz Carlos Assis (Org), Ouvidoria: mídia organizacional. Porto Alegre: Editora Sulina, 2012.

CLIENTESA/2013. Disponível em: <www.clientesa.com.br/especial>.

CNSP - Conselho Nacional de Seguros Privados, 2013-RN n²79.

KOTLER, Philip; ARMSTRONG, Gary. Princípios de Marketing. 7. ed. Rio de Janeiro: Editora LTC, 1999.

MARTINEZ, Wladimir Novaes. Primeiras lições de Previdência Complementar. São Paulo: LRT, 1996.

MERCER, Artigos Gama. 2015. Disponível em: <https://auditoriaatuarial.com.br>.

PLANALTO, Artigo 2010. Disponível em: www.planalto.gov.br/ccivic_03/leis/lcp109.htm

PREVIC - Superintendência Nacional de Previdência complementar. Guia Melhores Práticas - estrutura organizacional para as Fundações. 2010. Cap. 33, p. 18 - Governança.

2012. Disponível em: <http://www.previc.gov.br/e-previdencia-complementar-fechada/sobre-o-setor>.

VAVRA, T. G. Marketing de relacionamento: aftermarketing. São Paulo: Atlas, 1993.

VILANOVA, Maria; FAVE et al. (Org.). Ouvidoria universitária no Brasil: vinte anos de experiência. Florianópolis: Tribo da Ilha, 2012. 